\title{
Profissional da Informação: imagem, perfil e a necessidade da educação continuada
}

\author{
Neilia Barros Ferreira de Almeida ${ }^{i}$ \\ Sofia Galvão Baptista
}

Resumo: Apresenta o bibliotecário como profissional representante da família dos profissionais da informação, discute a classificação do profissional da informação da $\mathrm{CBO}$, estereótipo do bibliotecário perante a sociedade brasileira bem como o seu perfil. Ressalta a importância dos estudos realizados sobre o perfil do profissional da informação. As mudanças no perfil do bibliotecário nos últimos 10 anos (1998-2008) foram comparadas com os resultados do estudo de Baptista (1998) e o de Walter (2008).

Palavras-chave: Profissional da informação. Imagem do bibliotecário. Educação continuada do bibliotecário.

Abstract: Presents the librarian as an information professional family representative, discusses the CBO (Brazilian Occupation Classification) information professional classification, librarians stereotype image in Brazilian society and its profile. The discussion emphasizes information professionals profile and image. Baptista (1998) and Walter (2008) studies showed profile changes about 10 years

Keywords: Information professionals. Librarian image. Librarian continuing education

Resumen: Presenta al bibliotecario como profesional representante de la familia de los profesionales de la información, se discute la clasificación de los profesionales de la información de la CBO, el estereotipo del bibliotecario frente a la sociedad brasileña así como su perfil. Resalta la importancia de los estudios realizados sobre el perfil del profesional de la información. Los cambios en el perfil del bibliotecario en los últimos 10 años (1998-2008) fueron comparados con los resultados del estudio de Baptista (1998) y los de Walter (2008).

Palabras claves: Profesional de la información.Imagen del bibliotecário. Educación continuada del bibliotecário. 


\section{INTRODUÇÃO}

A informação seja explícita ou implícita sempre esteve presente na sociedade e em suas representações sociais. É inerente ao saber profissional, uma vez que toda profissão trabalha com a informação seja como atividade meio ou fim. Para Ortega y Gasset (2006) as profissões são trajetórias esquemáticas de vida, ou seja, são as carreiras ou caminhos de vida que encontramos já estabelecidos, notórios, definidos e regulamentados em nossa sociedade.

Da explosão informacional pós guerra, surgiu a sociedade da informação que se caracteriza pelo desenvolvimento da sociedade a partir da disponibilidade da informação organizada. Baseada na substituição da produção industrial pela informação, no conhecimento de novas tecnologias de informação (ARAÚJO; DIAS, 2008) e a inclusão social e digital.

O profissional da informação ao organizar e disseminar a informação exerce seu papel profissional para garantir a disponibilidade de informação para a sociedade. Le Coadic (1996) define os profissionais da informação como pessoas que adquirem a informação registrada em diferentes suportes, organizam, descrevem, indexam, armazenam, recuperam e fornecem essa informação em sua forma original ou como produtos elaborados a partir dela. O profissional é também um mediador entre os provedores de informação, os usuários e as tecnologias de informação (MORMELL, 1996 apud CASTRO, 2000).

Na literatura, o termo profissional da informação tem apresentado uma relação direta com a profissão de bibliotecário. Ao longo dos anos, a Biblioteconomia, assim como as outras áreas do saber, vem buscando seu reconhecimento social. No entanto, é fácil perceber que a sociedade brasileira tem uma imagem sobre o bibliotecário que não condiz, necessariamente, com que ela representa para a área da organização e disseminação da informação e suas contribuições para a educação e cultura. Os bibliotecários têm as bibliotecas como um mercado legalmente protegido, porém outros profissionais pertencentes à família dos "profissionais da informação" disputam o mercado da informação. De acordo com a Classificação Brasileira de Ocupações, são eles: documentalista, arquivistas e analistas de informação. ii

Na busca de se conhecer o perfil do bibliotecário e as suas representações sociais, foram realizados, ao longo dos anos, vários estudos sobre o perfil deste profissional. Para este estudo, foram selecionadas as teses de doutorado de Baptista (1998) e de Walter (2008). A partir da análise destes trabalhos é possível verificar as principais mudanças no perfil do bibliotecário brasileiro no período de 10 anos. 


\section{Profissional da informação}

Nos últimos anos, o termo profissional da informação está em evidência, alguns bibliotecários preferem se nomear como profissionais da informação do que como bibliotecários. Provavelmente, porque essa nomenclatura trás mais status ao profissional do que ser um bibliotecário. Isto pode ser observado na pesquisa de Walter $(2008$, p.240) onde uma bibliotecária afirma:

Há o estereótipo da bibliotecária velha de óculos, pedindo silêncio. Talvez em vez do nome bibliotecário, devíamos ser chamados de profissionais da informação ou outro nome.

O termo profissional da informação, frequentemente, é associado ao bibliotecário. Embora, os profissionais da informação não sejam apenas bibliotecários, mas sim uma família de profissionais que trabalham com a informação. Para Baptista (2009) os profissionais da informação são aqueles que lidam diretamente com a informação, ou seja, a informação é a atividade fim. Os profissionais considerados pela literatura como profissionais da informação são: jornalista, analista de sistema, desenvolvedor de software, webdesigner, bibliotecário, arquivista e museólogo. Confirmando a tendência de colocar essas profissões na mesma classificação, verifica-se que Le Coadic (2003) considera como as principais disciplinas da Ciência da informação: Biblioteconomia, Documentação, Museoconomia e Jornalismo.

Mueller (2004) define os bibliotecários, arquivistas e os mestres e doutores em Ciência da Informação como o núcleo de profissionais da informação. Guinchat e Menou (1994, apud MOTA; OLIVEIRA, 2008) acreditam haver uma unanimidade em torno dos profissionais com formação nas áreas de Biblioteconomia, Arquivologia e Museologia como as mais tradicionais.

Castro (2000, p. 6-7) sobre essa discussão afirma:

A Ciência da Informação constitui-se em uma ciência interdisciplinar, sendo algumas áreas mais próximas a ela como a Informática, a Arquivística, a Biblioteconomia, a Documentação, e a Comunicação, e outras atual na sua periferia a exemplo da Lingüística, Estatística, Sociologia e a Educação, dentre outras.

Mesmo observando certo grau de divergência entre os autores sobre quais são e quantos são, realmente, os profissionais da informação, percebe-se que há uma disputa pelo mercado de trabalho da informação e, para tal, Borges (2004) afirma que o bibliotecário precisa ter uma constante formação técnica, ter facilidade de interação com o mundo e especialistas, trabalhar em equipe e ter aprendizado autônomo.

O direito de posse das profissões, de acordo com Abbott (apud MUELLER, 2004) vem das arenas: legal, opinião pública e mercado de trabalho. Assim, uma profissão precisa de uma 
lei que a valide. Também é preferível que tenha um conselho profissional que possa lutar pelos seus direitos e cobrar deveres. O bibliotecário tem esses recursos para assegurar seu espaço, o problema acontece quando o espaço de trabalho não recebe o nome de biblioteca e sim, por exemplo: centro de informação, sala de leitura entre outros.

O espaço para a realização das atividades profissionais em relação à organização e disseminação da informação é amplo. Porém, a opinião pública tende a reduzir a tarefa profissional ao objeto livro e não a informação, ignorando suas complexidades. Da mesma forma que, quando uma profissão já está representada no imaginário da sociedade, qualquer mudança será processada muito lentamente (MUELLER, 2004).

\section{Imagem do bibliotecário}

É comum a sociedade criar estereótipos sobre as profissões. No caso da Biblioteconomia, o estereótipo se alicerça por meio da imagem de uma mulher solteira, de óculos, coque no cabelo, normalmente mal humorada.

Outra associação que surge no imaginário das pessoas é a figura do bibliotecário como "guardião do saber". Aquino (1987, apud CASTRO, 2000, p.5) afirma que "o papel deste profissional reduzia-se a vigiar coleções de manuscritos, de livros e outros impressos".

Com o avanço da tecnologia houve um aumento em relação ao número de cursos de biblioteconomia pelo país e um aumento do número de candidatos por vaga nos vestibulares. Na USP, a Biblioteconomia foi um dos cursos que teve o maior crescimento em relação à procura por vagas entre os anos 2005 e 2006. Boa parte deste interesse e atenção é atribuída à nova fase da Internet, como afirmou a professora Asa Fujino, coordenadora do curso de biblioteconomia da USP, em uma entrevista a João Loes (2007).

O moderno profissional da informação descrito por Guimarães (1997), muitas vezes, não se reconhece na imagem que sua profissão reflete no imaginário da população. A figura 1 tenta mostrar o paradoxo que há entre o bibliotecário e sua importância para o desenvolvimento social e cultural da sociedade e sua imagem (representação social) pela sociedade. Uma vez que a representação social da profissão é: mulher, mal humorada, solteira e com aversão a usuário (Walter, 2008). 


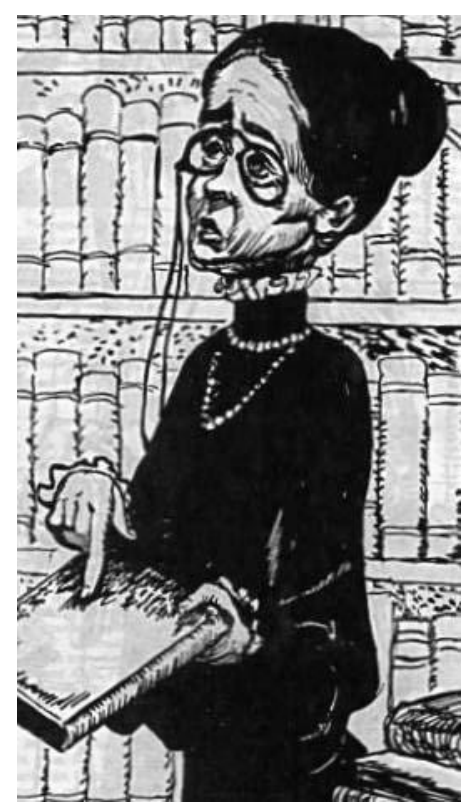

Fig . 1 estereótipo dos bibliotecários

\section{http://home.earthlink.net/ cyberresearcher/stereotypes.htm}

\section{(ALA- STEREOTYPES OF LIBRARIANS)}

A questão do estereótipo foi discutida por Walter (2008) e por Baptista (1998). A literatura traz explicações para o fenômeno. Walter (2008) utilizou a teoria da representação social de Moscoviciii que explica a criação dos estereótipos. Baptista (1998) menciona a explicação de Radford \& Radford (1997) que se basearam na teoria de Foucault para explicar o estereótipo criado para o bibliotecário. Na perspectiva desses autores a explicação está no "poder" que o bibliotecário tem dentro de um sistema de informação (biblioteca, centro de informação e similares) e a reação dos usuários a esse "poder".

Ainda sobre a questão feminina, os dados obtidos na pesquisa de Walter (2008) mostram que houve um aumento no número de homens na profissão e, que a maior parte dos bibliotecários (as) é casada. Essa realidade pode estar relacionada à tecnologia.

A identidade profissional pode ser estudada em função das características explicitadas pelo grupo, pelos reflexos sociais que produz, pelos valores que levam a constatação de existência de uma sociedade e pelas crenças que permeiam o imaginário de seus membros (CASTELLS, 2001 apud WALTER, 2004). 


\section{Estudos sobre o perfil do bibliotecário}

Muitos estudos foram realizados sobre o perfil do bibliotecário no Brasil nos últimos anos, entre os principais estão: Oliveira (1980); Tarapanoff (1997); Baptista (1998); Valentim (2002); Ferreira (2002); Walter (2008). ${ }^{\text {iv }}$

Os estudos citados mostram a questão do estereótipo do profissional, as atividades exercidas e as necessidades do profissional. Esses estudos foram de grande abrangência, em relação aos estudos sobre o profissional da biblioteconomia no Brasil. A pesquisa de Baptista (1998) Bibliotecário autônomo versus institucionalizado coletou 1473 respostas da área Sul e Sudeste e, em 2008, a tese de doutorado de Walter (2008) obteve 488 respostas.

\section{Perfil do bibliotecário: 1998 - 2008: estudos realizados por Baptista (1998) e Walter (2008)}

Com a finalidade de conhecer as principais mudanças no perfil do bibliotecário nos últimos 10 anos, foi realizada uma análise comparativa entre algumas variáveis comuns à pesquisa de Baptista (1998) e a de Walter (2008). A partir desta comparação, foi possível observar o perfil do bibliotecário atual e verificar se seu perfil se enquadra dentro das características refletidas na sociedade.

Em 1998, Baptista defendeu sua tese de doutorado, "Bibliotecário autônomo versus institucionalizado: carreira, mercado de trabalho e comprometimento organizacional". Na ocasião, foi realizada uma pesquisa com os bibliotecários da região Sul e Sudeste, que correspondiam a $71 \%$ dos bibliotecários do país. Foram enviados 10.376 questionários por meio de correio com o retorno de 1.447 (14,56\%) questionários recebidos.

Passados 10 anos, desde a realização deste estudo, Walter (2008) defendeu sua tese de doutorado, "Bibliotecários no Brasil: representações da profissão", na Universidade de Brasília. A pesquisadora realizou sua pesquisa com bibliotecários de todo país, exceto com os da região Norte, por não ter acesso ao cadastro de bibliotecários daquela região. Tanto na pesquisa de Baptista (1998) como na de Walter (2008) os dados sobre os profissionais entrevistados foram solicitados pelas pesquisadoras aos Conselhos Regionais de Biblioteconomia.

Walter enviou 3.973 questionários por meio de correio tradicional, correio eletrônico e disponibilizou o questionário na página dos sites de alguns dos CRBs. Foram recebidos 488 questionários representando 12,29\% do universo. A comparação dos dados obtidos por Walter (2008) com os obtidos por Baptista (1998) pode ser observada no quadro a seguir: 


\begin{tabular}{|l|l|l|}
\hline & \multicolumn{1}{|c|}{ BAPTISTA } & \multicolumn{1}{|c|}{ WALTER } \\
\hline Ano & 1998 & 2008 \\
\hline Regiões & Sul e Sudeste & $\begin{array}{l}\text { Sul, Sudeste, Nordeste e } \\
\text { Centro Oeste }\end{array}$ \\
\hline № de questionários enviados & 10.376 & 3.973 \\
\hline № de questionários recebidos & 1.477 (14.56\%) & $488(12,29 \%)$ \\
\hline Tipo de dados & Correio & Correio; E-mail; Internet \\
\hline & Qualitativos e quantitativos & Qualitativos e quantitativos \\
\hline
\end{tabular}

Quadro 1: Comparação entre as pesquisas de Baptista (1998) e Walter(2008)

A pesquisa de Baptista tinha como objetivos: determinar os motivos do surgimento de um mercado de trabalho alternativo para o bibliotecário; identificar as características da atuação do bibliotecário autônomo em comparação com a atuação do bibliotecário institucionalizado; identificar o mercado para os bibliotecários autônomos. Baptista (1998) buscou analisar separadamente as atividades, as necessidades e as demandas do bibliotecário institucionalizado e do bibliotecário autônomo em relação às habilidades necessárias e aos motivos da opção pela a área de negócio. Walter (2008) focalizou a percepção do bibliotecário sobre sua própria imagem e mercado de trabalho. Desse modo, a autora pesquisou de que forma os bibliotecários e o corpo docente, no Brasil, definem o que é o bibliotecário e qual é o seu mercado de trabalho, as competências necessárias para o profissional, quais as condutas morais e éticas apontadas como essenciais, as práticas mais utilizadas e quais os valores e crenças transmitidos pela prática pedagógica dos professores durante o curso.

\subsection{Paralelo entre os estudos: dados obtidos}

\subsubsection{A questão feminina}

É comum associar o profissional que trabalha em uma biblioteca com um profissional do sexo feminino. Os estudos comprovaram que a biblioteconomia é uma profissão predominantemente feminina. Para Martucci (1996) este fato se estabelece pelo elo que há entre a profissão de bibliotecário e o magistério. Uma vez que as duas profissões têm origem 
nos paradigmas da sociedade patriarcal que permitia que mulheres saíssem de casa para trabalhar em tarefas similares às do lar.

O estudo realizado por Baptista (1998) mostrou que a maioria (95\%) dos seus respondentes era mulher. Após um período de 10 anos, Walter (2008) tem quase o mesmo resultado, em sua amostra, $88 \%$ dos respondentes eram mulheres. Porém, a quantidade de homens na biblioteconomia cresceu, passando de 5\% para 12\% (WALTER, 2008).

\subsubsection{Faixa etária}

Na amostra de Baptista (1998), a maioria dos bibliotecários entrevistados concentravase na faixa etária de 30 a 49 anos. Enquanto na pesquisa de Walter (2008) a maior parte dos respondentes estava na faixa etária de 40 a 59 anos. Na pesquisa de Baptista (1998), a maioria dos profissionais da amostra tinha uma média de 15 anos de formados. Já em Walter (2008), houve um grande número de profissionais com menos de 10 anos de formação acadêmica.

\subsubsection{Avaliação do curso}

Baptista e Walter (2009) identificaram que os entrevistados que não gostaram da qualidade do curso de graduação encontram mais dificuldades no mercado de trabalho do que os que gostaram do curso. Os dois estudos verificaram que as pessoas formadas na década de 90 são mais pessimistas em relação ao mercado de trabalho do que os formados na década de 80 ou após 2000.

Possivelmente, isso pode ser explicado pelo o fato da tecnologia ter sido introduzida apenas na prática da Biblioteconomia ou pelo fato dos currículos não terem flexibilidade para acompanhar as mudanças na sociedade e, causando assim uma defasagem para o profissional. No entanto, esse profissional deveria procurar atualização por meio da educação continuada, mas esse é outro problema detectado pela literatura sobre a atuação do bibliotecário brasileiro (PROSDÓCIMO ; OHIRA, 1999) que mostram poucos investimentos nessa atividade.

\subsubsection{Unidade de informação}

Quanto ao tipo de unidade de informação que o bibliotecário trabalha, pode-se afirmar que, em 10 anos, a situação continua muito parecida. Baptista (1998) e Walter (2008) verificaram que a maior parte dos bibliotecários trabalhava em bibliotecas universitárias e bibliotecas especializadas que, possivelmente, pode ser explicado pela questão salarial. Nos dois estudos foi verificado que bibliotecas escolares e bibliotecas públicas pagam salários menores. Os resultados de Walter (2008) apontaram que os bibliotecários que atuam nessas instituições têm uma visão negativa em relação à biblioteconomia. Esse dado pode estar 
relacionado à situação das bibliotecas dos municípios brasileiros. Na prática, são bibliotecas esquecidas, deixadas de lado ou preteridas a qualquer outro tipo de instituição (MILANESI, 2002).

\subsubsection{Salários}

Em 1998, o salário mínimo era de $\mathrm{R} \$ 130,00$ e, na pesquisa de Baptista, mais de $60 \%$ dos bibliotecários recebiam mais de sete salários mínimos, ou seja, R\$910,00. Em 2008, o salário mínimo equivalia a $\mathrm{R} \$ 415,00$, apenas $36,9 \%$ dos bibliotecários, pesquisados por Walter, recebiam mais de sete salários, ou seja, $\mathrm{R} \$ 2.905,00^{\vee}$

\subsubsection{Oportunidades de trabalho}

Em 10 anos, os resultados de Walter (2008) mostram que os bibliotecários perceberam suas oportunidades de desenvolvimento diminuindo. Em 1998, 66,7\% afirmavam existir oportunidades de desenvolvimento e aprendizagem no trabalho executado (BAPTISTA 1998). Já em 2008 a porcentagem diminuiu para 49,7\% que afirmaram que onde trabalham existem oportunidades de crescimento na carreira e progresso profissional.

\subsubsection{Educação continuada}

Nas últimas décadas, a necessidade da educação continuada do profissional da informação tornou-se um tema comum na Biblioteconomia. Cunha (1984, p. 149-150) "o bibliotecário precisa reconhecer a necessidade e as vantagens da educação continuada para si próprio, para a instituição provedora de informação e, principalmente, para a comunidade a que atende".

Baptista (1998) em sua pesquisa identificou, em 1368 respostas, que 59,6\%, dos bibliotecários tinha apenas a graduação, $26,8 \%$ fez algum tipo de especialização 7,9\% tinham mestrado e 2,1\%doutorado. Em 2008, os dados obtidos mostraram um avanço em relação ao nível de escolaridade dos bibliotecários, Walter (2008) percebeu que o número de bibliotecários com especialização $(45,1 \%)$ é maior que o número de profissionais que tem apenas a graduação $(43,6 \%)$. Da mesma forma que há mais mestres e doutores em Biblioteconomia (10,8\%) do que em 1998.

Walter (2008) ao analisar os dados de sua pesquisa referentes às variáveis escolaridade e salário, verificou que os bibliotecários que possuem doutorado têm uma visão mais positiva do mercado de trabalho e encontram-se nas faixas salariais acima de $R \$ 3.000,00$. A partir desse resultado, é possível identificar que a educação continuada é um instrumento 
eficaz no que diz respeito à qualidade do trabalho desempenhado pelo profissional, seu reconhecimento no mercado de trabalho e, em especial, para visão positiva de sua imagem.

\section{Necessidade da educação continuada}

A educação não pode ser considerada conclusa ao final de um curso, mas sim um processo contínuo. Para Collet (1973) o homem em virtude da própria natureza é um ser inacabado e incompleto e a educação, quer espontânea, quer sistêmica, não pode ser considerada conclusa, pois é um processo permanente. Partindo deste princípio é necessário que um indivíduo esteja em constante processo de educação continuada.

Para Figueiredo (1993 apud CRESPO et al. 2006, p.4) os motivos que orientam a necessidade da educação continuada são:

O primeiro deles é a influência das tecnologias que, através de seus novos recursos criam, constantemente, demandas diferenciadas; 0 segundo são as modificações que foram refletidas pelo contexto sócio-econômico-político-cultural no qual os serviços bibliotecários são oferecidos.

A cada dia verifica-se a relevância de profissionais buscarem a educação continuada para aumentar o seu conhecimento, atualização, ou por imposição do mercado de trabalho. Independente da motivação é fundamental que o profissional pratique a educação contínua. Cunha (1984, p.150) afirma que o curso "serve como base para a criação do arcabouço de um indivíduo e, sem outros acréscimos e atualizações, essa base pode se tornar obsoleta em pouco tempo"

O investimento na educação continuada deve ser feito para acompanhar o ritmo das mudanças tecnológicas. Os currículos dificilmente acompanham as mudanças em tempo hábil para que os novos conhecimentos sejam introduzidos nos cursos de graduação (SOUZA, 2007). No entanto, a problemática não reside apenas na dificuldade das escolas de Biblioteconomia assimilarem e acompanharem as mudanças, mas na motivação do bibliotecário procurar a atualização em cursos de associações da classe ou pós-graduação.

A atual conjuntura impõe ao profissional maior domínio sobre tecnologias que se diversificam rapidamente. $\mathrm{O}$ que irá exigir do bibliotecário um aperfeiçoamento e renovação de seus conhecimentos. Porém, isso só ocorrerá se houver motivação pessoal. Moreno et al (2007, p.46) afirmam: "[...] isto é, deve haver uma necessidade do profissional se aperfeiçoar"

O ser humano só passa pelo processo de mudança quando o ambiente que está inserido exige que ele seja pró-ativo, ou seja, "capaz de interpretar dados e sinais emitidos 
pelos novos sistemas autômatos, agindo pró-ativamente a partir desses dados, atuando como agente do processo de inovação" (ARRUDA; MARTELETO; SOUZA, 2000, p. 17).

Walter (2008) verificou que os bibliotecários não se sentem valorizados pela sociedade. Partindo do princípio que quanto mais capacitado e proativo o profissional for, melhores serão seus serviços prestados à comunidade, o bibliotecário terá a chance de se promover perante o seu público nos ambientes em que há muita informação, avanços tecnológicos, inúmeros usuários com diferentes necessidades e um problema em comum: muita informação e necessidade de precisão na recuperação da informação.

A sociedade tende a simplificar as atividades de um profissional. Para mudar esta realidade é algo complexo e lento. Souza $(2007$, p.8) afirma:

[...] no sentido de retornar o papel do profissional como intelectual, abandonando o estigma que acompanha este profissional visto, na maioria das vezes, como um simples técnico.

O profissional é responsável pela imagem que reflete para a sociedade e observando a relevância de mudar esta imagem e se tornar um Moderno Profissional da Informação é necessário que o bibliotecário busque "um intenso processo de educação continuada" (CASTRO, 2000, p.9).

\section{Conclusão}

Embora a Biblioteconomia seja uma ciência que, na prática, existe há vários séculos, no Brasil, o bibliotecário só ganhou status de profissão e regulamentação na segunda metade do Século XX. No entanto a imagem do profissional já era algo formado no âmbito da sociedade brasileira.

A profissão bibliotecária, até o momento, conviveu com o estereótipo que a sociedade criou a seu respeito e, é provável que este ainda perdure por algum tempo. Porém, ao verificar alguns estudos sobre o perfil do bibliotecário e com um pouco de conhecimento sobre as atividades que desempenha é possível observar que a imagem de "guardião do saber" representada por Umberto Eco em seu romance histórico "O nome da rosa" é totalmente o oposto do que as atuais atividades biblioteconômicas oferecem.

Para NINA( 2006, p.14):

(....) em outras épocas predominava um entendimento, quase generalizado, de que os profissionais bibliotecários eram apenas os guardiões do conhecimento oficial e tradicional, verificou-se uma mudança considerável quando, no momento atual, eles são associados à disseminação da informação por meios virtuais. 
Pesquisas como a de Walter (2008) negam o estereótipo do profissional da "bibliotecária solteirona", uma vez que, na pesquisa de Walter 332 (69\%) respondentes informaram que eram casados, viúvos ou tinham uma união estável. No entanto, a profissão continua sendo predominantemente feminina, embora haja um crescimento considerável de profissionais do sexo masculino.

A característica que mais influência na imagem negativa que a opinião pública tem em relação ao bibliotecário é a falta de conhecimento e contato da maioria dos brasileiros com a biblioteca, o que está associado igualmente à falta de investimentos na educação. Afinal, não se pode valorizar o que não se conhece. Infelizmente, o bibliotecário sozinho não é capaz de fomentar as bibliotecas públicas e escolares do país. Porém, o que está ao seu alcance é aperfeiçoar-se por meio da educação continuada. E, individualmente ou em grupos, promover eventos de iniciativa a leitura, alfabetização digital entre outros, quando possível para realizar eficazmente o seu papel social.

\section{Referências}

ARAÚJO, Eliany Avarenga; DIAS, Guilherme Atayde de. A atuação profissional do bibliotecário no contexto da sociedade de informação: os novos espaços de informação. In: CEDÓN, Beatriz Valadares [ et al.]. Ciência da Informação e Biblioteconomia: novos conteúdos e espaços de atuação. Belo Horizonte: Editora UFMG, 2008. Cap. 6, p. 111-122.

ARRUDA, M. da C. C.; MARTELETO, R. M.; SOUZA, D. B. de. Educação, Trabalho e o delineamento de novos perfis profissionais: o bibliotecário em questão. Ci Inf., Brasília, v.29, n.3, p.14-24, set./dez. 2000.

BAPTISTA, Dulce Maria. Entre a informação e o sonho: o espaço da biblioteca contemporânea. Inf. \& Soc.: Est., João Pessoa, v. 1, p. 19-27, jan./abr. 2009.

BAPTISTA, Sofia Galvão. Bibliotecário autônomo versus institucionalizado: carreira, mercado de trabalho e comprometimento organizacional. 1998. 234f. Tese (Doutorado em Ciência da Informação)-Departamento de Ciência da Informação e Documentação, Universidade de Brasília, Brasília, 1998.

BORGES, Maria Alice Guimarães. O profissional da informação: somatório de formações, competências e habilidades. In: BAPTISTA, Sofia Galvão; MUELLER, Suzana Pinheiro Machado. (Org.). Profissional da informação: o espaço de trabalho. Brasília: Thesaurus/CID-UnB, 2004. (Estudos Avançados em Ciência da Informação, v.3).

BRASIL. Ministério do Trabalho. Classificação Brasileira de Ocupações. Brasília, 2002. Disponível e: <http://www.mtecbo.gov.br/cbosite/pages/pesquisas/BuscaPorTituloResultado.jsf > Acesso em: 26 jun 2009.

CASTRO, César Augusto. Profissional da informação: perfis e atitudes desejadas. Inf. \& Soc.: Est., João Pessoa, v. 10, n. 1, 2000. 
Disponível em: < http://www.ies.ufpb.br/ojs2/index.php/ies/article/view/346/268 > Acesso em: 28 jun. 2009.

COLLET, Heloísa Gouvêa. Educação permanente: uma abordagem metodológica. Rio de Janeiro: Serviço Social do Comércio Departamento Nacional, 1973.

CUNHA, Murilo Bastos. O desenvolvimento Profissional e a Educação continuada. $R$. Bibliotecon, Brasília, v.12, n.2, p.149-156, jul./dez. 1984.

CRESPO, I. M.; RODRIGUES, A. V. F.; MIRANDA, C. L. Educação continuada para bibliotecários: características e perspectivas em um cenário de mudança. Biblios, [S.I.], Año 7, n. 25-26, jul./dic. 2006.

GUIMARÃES, José Augusto Chaves. Moderno profissional da informação: elementos para sua formação no. Brasil. Transinformação, v.9, n.1, p.124/137, 1997

LE COADIC, Yves-François. A Ciência da Informação. Brasília: Briquet de Lemos/Livros, 1996 2.ed. Brasília: Briquet de Lemos/Livros, 2003. 124 p.

LOES, João. Profissão TI - Como a tecnologia tem revolucionado carreiras clássicas. UOL, [S.I], mar. $2007 . \quad$ Disponível em: <http://wnews.uol.com.br/site/noticias/materia_especial.php?id_secao=17\&id_conteudo=23 3 > Acesso em: out. 2010.

MARTUCCl, Elizabeth M. A feminização e a profissionalização do magistério e biblioteconomia: Uma aproximação. Perspectiva em Ciência da Informação, v.1, n.2, p.225-244, jul/dez. 1996

MILANESI, Luís. Biblioteca. Cotia, SP: Ateliê, 2002.

MORENO, E. A. ; MENDONÇA, T. C.; ALBERTOS, J. FARIAS, R.M. A formação continuada dos profissionais bibliotecários: análise do conteúdo ds sites das entidades de classe. Revista ACB: Biblioteconomia em Santa Catarina, Florianópolis, v.12, n.1, p.43-58, jan./jun., 2007.

MOTA, Francisco Rosaline Leite; OLIVEIRA, Marlene de. Formação e atuação Profissional. In: CEDÓN, Beatriz Valadares [et al.] Ciência da informação e Biblioteconomia: novos conteúdos e espaços de atuação. Belo Horizonte: Editora UFMG, 2008. Cap. 5, p.97-110.

MUELLER, Suzana Pinheiro Machado. Uma profissão em evolução: profissionais da informação no Brasil sob a ótica de Abbott - proposta de estudo. In: BAPTISTA, Sofia Galvão;

(Org.). Profissional da informação: o espaço de trabalho. Brasília: Thesaurus/CID-UnB, 2004. (Estudos Avançados em Ciência da Informação, v.3).

NINA, Renée Rosanne Vaz. Profissional da informação: o bibliotecário e suas representações das competências profissionais e pessoais para atuar em bibliotecas. Florianópolis, 2006. $258 \mathrm{f}$. Dissertação (Mestrado em Ciência da Informação) - Centro de Ciências da Educação, Universidade Federal de Santa Catarina.

OLIVEIRA, Márcio S. B. S. de. Representações sociais: a contribuição de Serge Mosocovici. Revista Brasileira de Ciências Sociais, v.19, n. 55. 2004

ORTEGA Y GASSET, José. Missão do bibliotecário. Tradução e posfácio de Antonio Agenor Briquet de Lemos. Brasília: Briquet de Lemos / Livros, 2006. 82 p. 
PROSDÓCIMO, Z. P. A. , OHIRA, M. L. B. Educação continuada do bibliotecário:revisão de literatura. Revista de Biblioteconomia em Santa Catarina v.4, n.4, p.111-128, 1999.

SOUZA, Elisabete Gonçalves de. A formação continuada do bibliotecário face às exigências das novas tecnologias. 2007. Disponível em:

< http://www.alb.com.br/anais16/sem02pdf/sm02ss04_01.pdf> Acesso em:1 jul 2009

RADFORD, M.; RADFORD, G. P. Power, knowledge, and fear: feminism, Foucault, and stereotype of female librarian. Library Quarterly, v.67, n.3, p.250-266, jul. 1997.

WALTER, Maria Tereza Teles. Bibliotecários no Brasil: representações da profissão. 2008. 345 f. Tese (Doutorado em Ciência da Informação)-Departamento de Ciência da Informação e Documentação, Universidade de Brasília, Brasília, 2008.

Identidades, valores e mudanças: o poder da identidade profissional. Os bibliotecários subsistem na era da informação? Em Questão. Porto Alegre, v. 10, n.2, p. 287 - 299, jul./dez. 2004.

; BAPTISTA, Sofia Galvão. Representações profissionais de bibliotecários no Brasil: alguns resultados de pesquisa. Enc. Bibli: R. Eletr. Bibliotecon Ci Inf., Florianópolis, v.14, n.27, 2009, p. 22-46.

\section{Notas}

' (1) Aluna do mestrado do Programa de Ciência da Informação da Faculdade de Ciência da Informação (2) professora orientadora e líder do Grupo de pesquisa "Mercado de trabalho do profissional da informação"

' Família: Profissional da Informação:

Código 2612-05 - Bibliotecário Biblioteconomista, Bibliógrafo, Cientista de informação, Consultor de informação, Especialista de informação, Gerente de informação, Gestor de informação;

2612-10 - Documentalista Analista de documentação, Especialista de documentação, Gerente de documentação, Supervisor de controle de processos documentais, Supervisor de controle documental, Técnico de documentação, Técnico em suporte de documentação

2612-15 - Analista de informações (pesquisador de informações de rede) Pesquisador de informações de rede

Disponível em: <http://www.mtecbo.gov.br/cbosite/pages/pesquisas/ResultadoFamiliaDescricao.jsf> Acesso em: 23 jul.2010

\footnotetext{
iii Oliveira (2004) afirma que Moscovici, em suas próprias palavras, interessou-se no "poder das idéias" de senso comum, isto é, no "estudo de como, e por que as pessoas partilham o conhecimento e desse modo constituem sua realidade comum, de como eles transformam idéias em práticas [...]" Moscovici (apud Duveen,p. 8) em síntese, preocupou-se em compreender como o tripé grupos/atos/idéias constitui e transforma a sociedade.
}

iv (1) OLIVEIRA, Zita Catarina Prates de. Um estudo da auto imagem profissional do bibliotecário. 1980. (2) TARAPANOFF, Kira. Perfil do profissional da informação no Brasil. Brasília: Iel/DF, 1997. 134p. (3) VALENTIM, Marta Lígia (Org.). Formação do profissional da informação. São Paulo: Polis, 2002(4)FERREIRA, Danielle Thiago. Profissional da informação: perfil de habilidades demandadas pelo mercado de trabalho. 2002. 114 f. Dissertação (mestrado) - Pontifícia Universidade Católica de Campinas. 109f.

v Walter (2008) e Baptista (1998) utilizaram faixas salariais diferentes 